\title{
105. Nature of the Negative Inotropic Effect of Acetylcholine on the Myocardium
}

\author{
An Elucidation on the Bullfrog Atrium
}

\author{
By Yoshimi IKemoto and Masayosi Goto \\ Department of Physiology, Faculty of Medicine, Kyushu University, Fukuoka
}

(Comm. by Kenji Yamaoka, M. J. A., June 3, 1975)

Acetylcholine ( $\mathrm{ACh}$ ) has long been known to produce a negative inotropic effect on the myocardium. The cause of the effect was attributed to the shortened action potential (Antoni and Rotmann, 1968) elicited by an increase in potassium conductance of the myocardial cell membrane (Trautwein and Dudel, 1958). Recently, however, a possibility of decrease in calcium inward current by $\mathrm{ACh}$ was suggested in the canine and rabbit left auricles (Prokopczuk et al., 1973). In order to settle the problem, present experiments studied the effects of ACh on the membrane potentials, currents and contractile tensions of the atrial muscle of the bullfrog under voltage clamp or unclamped conditions, since two components of contractile tension of the myocardium have been documented with these methods; the phasic component, attributed to the slow calcium inward current and the tonic component, unrelated to the current (Vassort and Rougier, 1972; Léoty and Reymond, 1972; Goto, Wada and Saito, 1974).

By the use of double glycerol gap method, gap action potential and contractile tension of thin bundles of the atrium were recorded simultaneously (Goto, Wada and Saito, 1974). The width of central test chamber was $0.6 \mathrm{~mm}$ which was less than the $\lambda$ determined by similar gap method (Noble, personal communication). In voltage clamp experiments the membrane currents and contractile tensions were measured simultaneously, with or without TTX $\left(10^{-6} \mathrm{~g} / \mathrm{ml}\right)$. All experiments were performed at room temperature around $17^{\circ} \mathrm{C}$. The test chamber was normally perfused with Ringer's solution of the following composition ( $\mathrm{mM}) ; \mathrm{NaCl}$ 105.0, $\mathrm{KCl}, 2.5, \mathrm{CaCl}_{2}$ 1.8, glucose 5.0, and Tris $\mathrm{Cl} 10.0 . \mathrm{pH}$ of the solution was adjusted to be 7.4. The clamp pulses were applied at the basal rate of $0.1 / \mathrm{sec}$.

When ACh $\left(10^{-6} \mathrm{~g} / \mathrm{ml}\right)$ was introduced the amplitude of gap action potential was slightly reduced without any change in resting membrane potential. The duration of action potential, the peak tension of contraction and the time to peak tension were markedly 

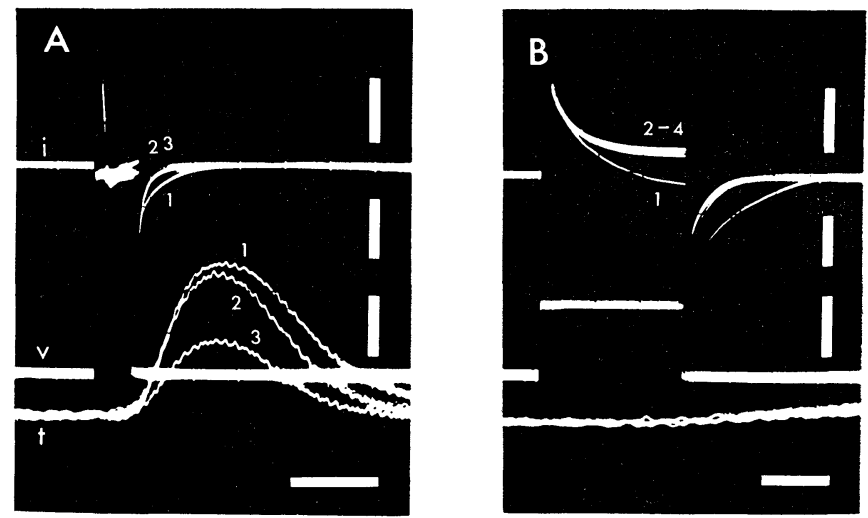

Fig. 1. Reduction in contractile tensions and inward currents of the atrial muscle by $\mathrm{ACh}\left(10^{-6} \mathrm{~g} / \mathrm{ml}\right)$ under voltage clamp. Depolarizing pulses of $100 \mathrm{msec}$ in duration and $70 \mathrm{mV}$ in amplitude were given from the holding potential of $-70 \mathrm{mV}$. A) Superimposed records of the membrane currents (i), voltages (v) and contractile tensions ( $t$ ) immediately before (1), $0.5 \mathrm{~min}$ (2) and $4 \mathrm{~min}$ (3) after application of ACh. Note a marked negative inotropic effect and a decrease in the tail current. B) Similar but faster records under the presence of TTX $\left(10^{-6} \mathrm{~g} / \mathrm{ml}\right)$. The records (1) and (2) to (4) are those taken before and 2 to $5 \mathrm{~min}$ after the application, respectively. The slow inward current and its tail were decreased markedly by ACh. Vertical bars are calibrations of $20 \mu \mathrm{A}, 20 \mathrm{mV}$ and $0.02 \mathrm{~g}$ for $\mathrm{A}$, and $5 \mu \mathrm{A}, 50 \mathrm{mV}$ and $0.02 \mathrm{~g}$ for $\mathrm{B}$. Horizontal bars mark $250 \mathrm{msec}$ for $A$ and $50 \mathrm{msec}$ for $B$.

decreased by ACh. In the voltage clamp experiments (Fig. 1A) the peak tension of contraction in response to a short $100 \mathrm{msec}$ depolarizing pulse was elucidated to be reduced by $\mathrm{ACh}$, although the pulse was not changed at all. It must be noted also that the time to peak tension was not altered in these conditions. Fig. 1B shows the slow inward currents and their tails (with TTX $10^{-6} \mathrm{~g} / \mathrm{ml}$ ) which were also decreased by ACh. These maximal tail currents measured at $-70 \mathrm{mV}$ level after the pulse are plotted as function of the amplitude of preceding depolarizations (Fig. 3A). Since in such a case of short pulse there is no major shift of the reversal potential of calcium ions, $\mathrm{E}_{\mathrm{Ca}}$ (Bassingthwaighte and Reuter, 1972; Trautwein, McDonald and Tripathi, 1975), the tail currents are directly proportional to calcium conductance, $\mathrm{g}_{\mathrm{Ca}}$. The normalization of these plots gives a steady state activation variable, $d_{\infty}$ (Fig. 3C). The time constant of d was slightly decreased by ACh.

The phasic component of contraction triggered by a short depolarizing pulse $(100 \mathrm{msec}, 70 \mathrm{mV})$ was greatly decreased by ACh, while the tonic component elicited by a long large pulse ( $1 \mathrm{sec}$, $140 \mathrm{mV}$ ) was rather enhanced (Fig. 2). The contracture tensions 

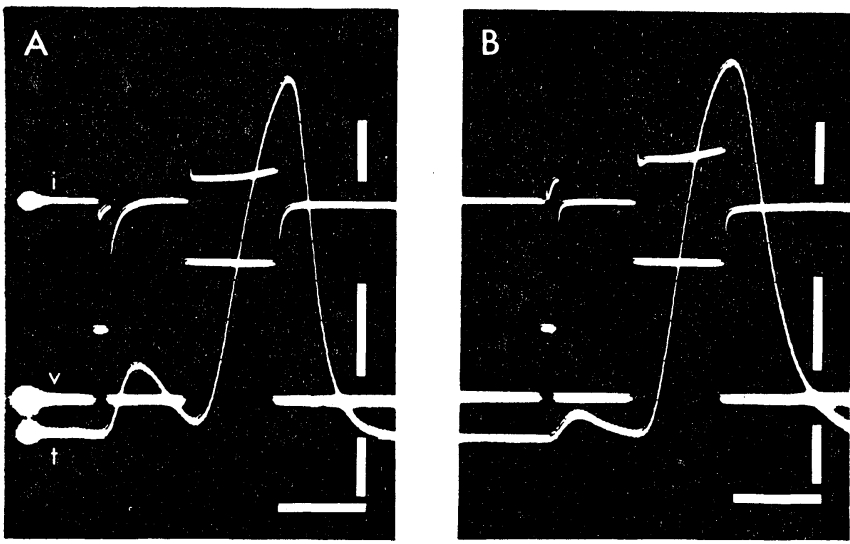

Fig. 2. Effects of $\mathrm{ACh}\left(10^{-6} \mathrm{~g} / \mathrm{ml}\right)$ on the phasic and tonic components of contractile tension. A) Control records. The membrane currents (i), voltages (v) and contractile tensions (t) in response to a short weak pulse $(100 \mathrm{msec}, 70 \mathrm{mV})$ and a long strong pulse $(1 \mathrm{sec}, 140 \mathrm{mV})$ were shown. B) Similar records 5 min after application of $\mathrm{ACh}$. The phasic tension component was markedly reduced in the presence of the drug while the tonic component was rather enhanced. Vertical bars are calibrations of $20 \mu \mathrm{A}$, $100 \mathrm{mV}$ and $0.05 \mathrm{~g}$ for the current, voltage and tension records, respectively. Horizontal bar marks 1 sec.

elicited by Na-free Ringer solutions were also enhanced by ACh. As these contracture tensions and the tonic component of contraction are known to be due to $\mathrm{Na}-\mathrm{Ca}$ exchange across the cell membrane and/or between the intracellular compartments (Lüttgau and Niedergerke, 1958; Goto, Wada and Saito, 1974), it may be concluded that $\mathrm{ACh}$ does not reduce the tension component which is not related to the slow calcium inward current.

The steady state inactivation variable of $g_{\mathrm{Ca}}, f_{\infty}$, was determined by measuring the tail current of $120 \mathrm{msec}$ pulse which was always depolarized to $0 \mathrm{mV}$ and applied at the end of conditioning pre-steps of $1 \mathrm{sec}$ duration to different potentials (Fig. $3 \mathrm{~B}$ inset). As an increase in potassium conductance, $g_{K}$, is well known effect of ACh, the precise measurement of slow inward current under the presence of the drug seemed to be impossible. The outward current of frog atrial muscle contains an anomalous rectification and two components of delayed rectification, $i_{1}$ and $i_{2}$ (Brown and Noble, 1969). The time constant of $i_{1}$ at $-90 \mathrm{mV}$, however, appeared considerably long to be $500 \mathrm{msec}$ and that of $i_{2}, 5 \mathrm{sec}$. The reversal potential of $i_{1}$ was also reported to lie between $-70 \mathrm{mV}$ and $-40 \mathrm{mV}$. Because we measured the tail inward currents always at $-70 \mathrm{mV}$, the interference of the outward currents with the tail current could be neglected. 
A

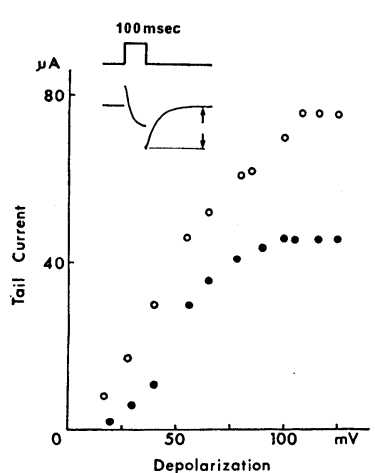

C

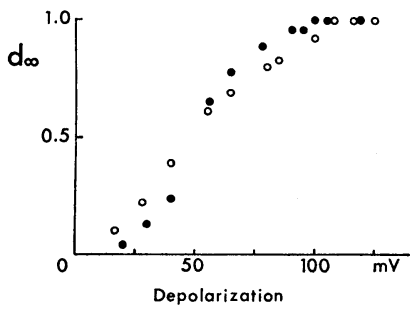

B

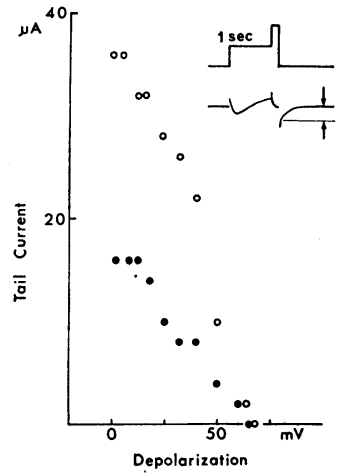

D

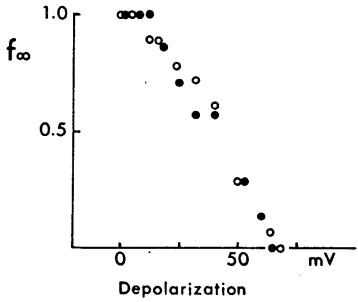

Fig. 3. Relationship between the amplitudes of the tail of slow inward current and the depolarizing pulse in the presence of TTX $\left(10^{-6} \mathrm{~g} / \mathrm{ml}\right)$. $\bigcirc$ : Control, $\bullet$ : Data under action of $\mathrm{ACh}$ $\left(10^{-6} \mathrm{~g} / \mathrm{ml}\right)$. A) Activiation, and B) Inactivation of $\mathrm{g}_{\mathrm{Ca}}$. Insets in the upper part of the figures show the methods used to obtain these variables. Note a marked decrease of the maximal tail current to $60 \%$ in A and $45 \%$ in B. C) Steady state activation variable $d_{\infty}$, a normalized plots of $A$. D) Steady state inactivation variable $f_{\infty}$, a normalization of $B$. Both $d_{\infty}$ and $f_{\infty}$ were not affected by ACh.

As shown in Fig. 3A, the size of tail currents activated by the depolarization pulses was markedly decreased by ACh. The decrease was more than $40 \%$ in cases of depolarization above $120 \mathrm{mV}$. This maximal change in tail current corresponds to the change in the limiting conductance of calcium ions, $\overline{\mathrm{g}}_{\mathrm{Ca}}$.

Fig. $3 \mathrm{C}$ and $\mathrm{D}$ show the steady state activation variable $\mathrm{d}_{\infty}$ and the steady state inactivation variable $f_{\infty}$, respectively. Reuter (1974) described the slow calcium inward current, $\mathrm{I}_{\mathrm{Ca}}$, as follows,

$$
\mathrm{I}_{\mathrm{Ca}}=\mathrm{g}_{\mathrm{Ca}}\left(\mathrm{E}_{\mathrm{m}}-\mathrm{E}_{\mathrm{Ca}}\right)
$$

in which $\mathrm{E}_{\mathrm{m}}$ denotes the membrane potential and $\mathrm{E}_{\mathrm{Ca}}$, the equlibrium potential of calcium ions, and then,

$$
\mathrm{g}_{\mathrm{Ca}}=\overline{\mathrm{g}}_{\mathrm{Ca}} \cdot \mathrm{d}_{\infty} \cdot \mathrm{f}_{\infty}
$$

In these kinetic terms only $\overline{\mathrm{g}}_{\mathrm{Ca}}$ was found to be reduced by $\mathrm{ACh}$. 
It may be concluded that $\mathrm{ACh}$ exerts its negative inotropic effect on myocardium not only by a shortening of action potential due to an increase in $g_{K}$ but also by a decrease in calcium inward current. The decrease in $I_{\mathrm{Ca}}$ is brought about not by changes in conductance variables $\left(d_{\infty}\right.$ and $\left.f_{\infty}\right)$ but by the reduction in $\bar{g}_{\mathrm{Ca}}$.

\section{References}

1) Antoni, H., and Rotmann, M. (1968): Zum Mechanismus der negative inotropen Acetylcholin-Wirkung auf das isolierte Froschmyokard. Pflügers Arch., 300, 67-86.

2) Bassingthwaighte, J. B., and Reuter, H. (1972) : Calcium movements and excitation-contraction coupling in cardiac cells. Electrical Phenomena in the Heart (edited by De Mellow, W. C.), p. 353-395.

3) Brown, H. F., and Noble, S. J. (1969): A quantitative analysis of the slow component of delayed rectification in frog atrium. J. Physiol., 204, 737747.

4) Goto, M., Wada, Y., and Saito, M. (1974) : Tension components and tension fall of the bullfrog atrial muscle during depolarization. Jap. J. Physiol., 24, 359-375.

5) Léoty, Cl., and Reymond, G. (1972): Mechanical activity and ionic currents in frog atrial trabeculae. Pflügers Arch., 334, 114-128.

6) Lüttgau, H. C., and Niedergerke, R. (1958): The antagonism between Ca and $\mathrm{Na}$ ions on the frog's heart. J. Physiol., 143, 486-505.

7) Prokopczuk, A., Lewartowski, B., and Czarnecka, M. (1973) : On the cellular mechanism of the inotropic action of acetylcholine on isolated rabbit and dog atria. Pflügers Arch., 339, 305-316.

8) Reuter, H. (1974) : Localization of beta adrenergic receptors, and effects of noradrenaline and cyclic nucleotides on action potentials, ionic currents and tension in mammalian cardiac muscle. J. Physiol., 242, 429-451.

9) Trautwein, W., and Dudel, J. (1958): Zum Mechanismus der Membranwirkung des Acetylcholin an der Herzmuskelfaser. Pflügers Arch., 226, 324-334.

10) Trautwein, W., McDonald, T. F., and Tripathi, O. (1975) : Calcium conductance and tension in mammalian ventricular muscle. Pflügers Arch., 354, 55-74.

11) Vassort, G., and Rougier, O. (1972): Membrane potential and slow inward current dependence of frog cardiac mechanical activity. Pflügers Arch., 331, 191-203. 